\title{
Association of Waist Circumference With Blood Pressure and Familial Dietary Habits in Preschool Children: A Cross-Sectional Study in Northeastern China.
}

\section{Xiao Tang}

China Medical University https://orcid.org/0000-0003-1941-9437

\section{Yang Liu}

China Medical University

Jiajin Hu

China Medical University

Lingling Zhai

China Medical University

Lihong Jia

China Medical University

Ning Ding

China Medical University

\section{Yanan Ma}

China Medical University

Deliang Wen ( $\nabla$ dlwen@cmu.edu.cn )

China Medical University

\section{Research}

Keywords: Blood pressure, waist circumference, waist-to-height ratio, body mass index, diet

Posted Date: June 8th, 2021

DOI: https://doi.org/10.21203/rs.3.rs-569902/v1

License: (c) (i) This work is licensed under a Creative Commons Attribution 4.0 International License.

Read Full License

Version of Record: A version of this preprint was published at Italian Journal of Pediatrics on April 1st, 2022. See the published version at https://doi.org/10.1186/s13052-022-01236-3. 


\section{Abstract}

\section{Background}

Childhood obesity increases the risk of elevated blood pressure (BP) in children. However, which obesity indicator is most closely associated with BP remains debatable. Moreover, the familial dietary environments play important roles on obesity, but which dietary factors are strong and independent ones for childhood obesity is unclear. Our study aimed to determine the superior indices associated with BP among body mass index (BMI), waist circumference (WC) and waist-to-height ratio (WHtR). Then, determine the independent familial dietary factors for those superior indices.

Method

605 children aged 2 to 6 , as well as their parents were involved in this study. The children's weights, heights, WC and BP were measured. Information on familial environments was obtained by asking the parents to complete questionnaires. BMI, WC and WHtR were standardized into their standardized z-score values and categorical variables of these three obesity indices were defined as BMI Category, WC Category and WHtR Category. Logistic regression was used to analyze the associations between standardized zscore of BMI, WC, WHtR and elevated BP. Multivariate stepwise linear regression and multivariate stepwise logistic regression were used to determine the independent factors for obesity indicators that were closely with BP.

Results

Numerical obesity indices associated with BP were, in order of decreasing association: WC, BMI and WHtR. The categorical variable that most closely associated with BP was WC Category. Parental BMI, birth weight of children, eating wheat as staple food, appetite, eating speed, snacking while watching TV, parental encouragement to eat a diverse assortment of foods and drinking milk were independent factors for WC in males or females. The risk of abdominal obesity would increase 1.375 times in males and 1.631 times in females if appetite increased one level. If eating speed increased one level, the risk of abdominal obesity would increase 1.165 times in males and 0.905 times in females. Children who drank milk greater than 6 times per week had a 0.546 times lower risk of abdominal obesity than those did not.

Conclusion

WC had the closest association with BP. Besides genetics, familial diet were independent factors for WC and abdominal obesity in preschool children.

\section{Background}

Hypertension is a common chronic disease in today's society. There is an abundance of evidence suggesting that elevated blood pressure (BP) during childhood can increase the individual's risk of having hypertension in adulthood[1,2]. Preventing elevated BP in children is beneficial in controlling the 
prevalence of hypertension in adults, which can in turn, decrease adult mortality due to cardiovascular diseases $[3,4]$.

For a long time, obesity has been recognized as an important cause of elevated BP in children [5-7]. Recent studies have attempted to determine the best maker of elevated blood pressure among anthropometric parameters such as body mass index (BMI), waist circumference (WC) and waist-to-height ratio (WHtR). $\mathrm{BMI}$ is the most common index used to predict elevated BP $[7,8]$. However, BMI cannot fully express the distribution of an individual's body fat. WC is commonly used to describe abdominal obesity. Some studies have shown that WC is strongly associated with elevated BP during childhood, as well as other cardiovascular diseases in adulthood $[9,10]$. WC has, at the least, become one of many indices of metabolic abnormalities among adults. WHtR is a waist-circumference-related index that considers height. Some studies have pointed out that WHtR plays an important role in predicting elevated blood pressure or risk of cardiovascular diseases during childhood $[11,12]$. However, the result on the magnitudes of association of BMI, WC and WHtR with elevated BP in childhood is inconclusive. Some studies have suggested that BMI, WC and WHtR have no difference in predicting childhood hypertension, whereas others have insisted on the difference between these indictors [6,13]. In addition, in previous studies investigating the relationship between obesity indices and elevated BP in children, the indices analyzed were either only numerical variables or only categorical variables. This may be one of the reasons for the inconsistency. Therefore, which adiposity indicator, WC, BMI, WHtR and their categorical indicators, is most strongly associated with elevated blood pressure in children need further investigation. Moreover, most research has studied school-age children and adolescents, studies on preschool children are very limited.

Since obesity is thought to cause elevated BP, it is necessary to explore the risk factors for obesity among preschool children. Many studies have also shown that the familial dietary environments including diet patterns, eating behaviours and parental feeding practice have large impacts on children's weights [14-17]. With respect to diet pattern, China has experienced rapid economic and social development over three decades, and a huge change in the foods consumption and components occurred. The dietary patterns have transited from traditional to Westernized ones. People have reduced the consumption of vegetables and whole grains and increased the consumption of red meat, processed meat, refined grain, sugar sweetened beverages, saturated fat and fried food, which leads to the growth the prevalence of obesity, diabetes and cardiovascular disease $[18,19]$. In addition, habitants in northeastern China prefer the typical northern Chinese diet which involves eating root vegetables, foods high in sugar and fat, wheat and wheatbased products as staple food, as well as the modern diet (high intake of milk, fast food and eggs). These two diet patterns are more likely to cause obesity, as compared to the diet pattern in southern China (high intake of vegetables, rice and pork) [20].

There is strong evidence suggesting that eating behaviours play an important role on childhood obesity. Many studies have investigated association of obesity with eating behavior [21,22]. Most of these studies found that some eating behaviours such as higher responsiveness to internal satiety cues and slowness in eating are negatively correlated with obesity, whereas other eating behaviours, such as eating in response 
to environmental food cues and food enjoyment, are positively correlated with obesity $[17,18]$. In addition, unhealthy eating behaviours such as eating quickly, eating while watching TV and snack while watching TV have been reported as contributing factors on childhood obesity $[22,23,24]$. Previous studies have claimed that a fast eating speed interfere with the reflex signal that tells the body to stop eating when the stomach is full, which led to more food intake but lower satiety [23]. Eating or snacking while watching TV increases the energy intake due to overeating in front of TV [25].

Parents can have direct control over the child's diet, so the familial dietary environment is also influenced by parental restrictions and guidance. Parental feeding practices reflect their attitudes toward nutritional science. The most important nutritional parenting practices includes limiting certain types of food, encourage or ask child to eat a diverse range of foods, food as a reward and food availability at home $[21,22,24]$. As demonstrated in many researches, parental restrictions and guidance on diet determine the amount and type of foods the child ingests, and therefore, are associated with children's weight [26,27]. Generally, an uninvolved, highly protective or strict parenting style is associated with higher BMI in children, while authoritative parenting is associated with healthy BMI $[26,27]$.

Although there are plenty studies analyzing the relationship between familial dietary environments and childhood obesity, most of the studies only focused on one aspect of diet, such as eating behaviours, diet pattern or parental feeding practices. However, among the numerous factors in multiple dimensions, which familial dietary factors are independent factors for childhood obesity is unclear. Our study first compared the magnitude of associations between BMI, WC, WHtR and elevated BP in preschool children. Then, we determined independent familial factors for obesity indices that were the most strongly associated with elevated BP, offering important variables to target in preventing elevated BP among preschool children.

\section{Methods}

\section{Participants}

The participants of this study were preschool children aged 2-6 in Shenyang, China. Multi-stage sampling was used to select the sample. From the seven districts in Shenyang, four were randomly selected. From each of the four districts, two kindergartens were randomly selected. Convenience sampling was employed to select one class from each grade in each kindergarten, yielding a total of 635 children. Physical examinations were performed on these children, and their parents were asked to complete the questionnaires. Children were excluded from the study if: (1) Their parents' ethnicities were not Chinese; (2) Their age was not between 2-6; (3) They had developmental diseases; (4) Their parents refused to give consent; (5) Their parents could not complete the questionnaires. Finally, 605 children and their parents participated in this study.

This study was approved by the Ethics Committee of Institute of Health Science (Ethics Approval No. [2017] 055), China Medical University.

\section{Measurements}




\section{Dependent variable}

The dependent variable of the first aim was BP. The physical examinations were conducted by trained and licensed doctors during school time. The children rested for at least 5 minutes before their blood pressures were taken. Blood pressures were measured by using an auscultation mercury sphygmomanometer with an appropriate cuff size. The systolic pressure was recorded as the pressure when the sphygmomanometer made the first Korotkoff sound. The diastolic pressure was taken when the sphygmomanometer made the fifth Korotkoff sound. BP was measured twice for each child and the average was taken. Based on the gender- and age-specific distribution of Chinese children's blood pressures [28], elevated BP was defined as having either systolic or diastolic pressure above the $90^{\text {th }}$ percentile, and normal BP was defined as both systolic and diastolic pressures below the $90^{\text {th }}$ percentile. A discrete variable was created with 'normal $\mathrm{BP}$ ' being the reference group $(0=$ normal $\mathrm{BP}$ and $1=$ elevated $\mathrm{BP})$.

The dependent variables of the second aim were obesity indexes. Heights and weights were measured with the children standing up, barefoot and wearing under garments. BMI was calculated as weight $(\mathrm{kg})$ divided by the square of height $(\mathrm{m})$. According to the gender- and age-specific BMI cutoff points provided by the Obesity Working Group, China (OWGC) [29], subjects were classified into one of three categories: healthy weight, overweight or obesity. We created a discrete variable "BMI Category" ( $0=$ healthy weights, $1=$ overweight or obesity).

WC was measured by wrapping a nonelastic flexible measuring tape around children's waists, $1 \mathrm{~cm}$ above the navel. The measurements were taken at normal expiration. Children whose WC was above the genderand age-specific $80^{\text {th }}$ percentile provided by OWGC were determined to be abdominally obese [30]. We created a discrete variable "WC Category" ( $0=$ not abdominally obese, $1=$ abdominally obese).

WHtR was calculated as waist circumference $(\mathrm{cm})$ divided by height $(\mathrm{cm})$. Children whose WHtR was greater or equal to 0.5 were determined to be abdominally obese. The variable "WHtR Category" was defined as a discrete variable, which was 0 if WHtR was less than 0.5 , and 1 if WHtR was greater or equal to 0.5 .

Because males and females have different distributions of BMI, WC and WHtR values, we standardized these three obesity indices. Based on the gender- and age-specific averages and standard deviations of BMI, WC and WHtR provided by OWGC, BMI, WC and WHtR values were standardized into standardized zscore values ZBMI, ZWC, and ZWHtR, respectively $[29,30]$. Standardized $Z$-score values for BMI, WC and WHtR were all calculated as:

$$
z=\frac{\text { value }- \text { mean }}{\text { Standard deviation }}
$$

\section{Questionnaires and independent variables}


A self-designed questionnaire was used, and the parents were asked to complete the questionnaire. The questionnaire asked about children's and parents' demographic information, children's food preferences, children's eating behaviours, parental control of children's diets, children's sleep duration and children's levels of physical activity.

Demographic information included: the child's age and gender, parents' heights, weights, levels of education and familial income. Paternal BMI and maternal BMI were calculated. Familial income level was recorded as $<3000$ yuan, 3000 to 5000,5000 to 8000 , >8000. Parents' education was categorized into three levels: secondary school or less, college or bachelor's degree and graduate degree. The child's age, paternal BMI and maternal BMI were used as continuous variables, and familial income level and parents' education were used as dummy variables in the regression models.

The familial dietary information included the child's food preferences, eating behaviours and parental control and guidance on the children's diets. The child's food preferences: parents were asked whether their child normally eat wheat and wheat-based products as their staple food ( $0=$ no, $1=y e s)$. They also answer how many times a week their child eats deep-fried food, potatoes and other root vegetables, milk products, desserts and sweets, nuts and puffed food. The child's eating behaviours included: eating speed ( $1=$ slow, $2=$ average, $3=\mathrm{fast})$, whether they watch TV while eating $(0=y e s, 1=$ no), whether they snack while watching TV ( $0=$ yes, $1=$ no) and appetite ( $1=$ good, $2=$ average, $3=$ poor $)$. Parental control and guidance on the children's diets included: whether they limit the amounts of snacks their child eats $(0=y e s, 1=n o)$, whether they use food as rewards ( $0=y e s, 1=$ no), whether they encourage their child to eat a diverse assortment of foods ( $0=y e s, 1=$ no).

Sleep duration is the amount of sleep the child gets during the night combined with the amount of sleep the child gets during the day (in hours). The amount of physical activity the child gets is the total amount of physical activity in a day (in hours).

\section{Statistical analysis}

Numerical variables in normal distribution were expressed by mean and standard deviation, and numerical data of skew distribution was expressed by percentile. Categorical variable was showed by frequency and percentage. The difference of ZWC between elevated and normal BP group was analyzed by two samples $t$ test, and the difference of ZBMI and ZWHtR between these two groups was analyzed by Wilcoxon MannWhitney test. The difference of prevalence of overweight and abdominal obesity between elevated and normal BP group was analyzed by chi-squared test. Logistic regression was used to analyze the association between obesity indices (ZBMI, ZWC, ZWHtR, BMI Category, WC Category, WHtR Category) and elevated $\mathrm{BP}$ in preschool children. Elevated $\mathrm{BP}$ was the outcome variable in the logistic regression, and five models were constructed. Each model included two different obesity indices which were both numerical or categotical to compare the sensitivity of the indices to elevated BP. All models were adjusted by age and amount of physical activity. 
In order to investigate the relationship between familial factors and the obesity indices, ZWC and WC category were used as dependent variables in the linear regression and logistic regression, respectively. First, each independent variable was entered in the univariate regression and variables that yielded a $\mathrm{P}$ value less than 0.2 were remained. Second, a multivariate stepwise linear regression and a multivariate stepwise logistic regression containing independent variables remained from the previous step were then performed to find the independent factors for ZWC and WC Category, respectively.

Excel 17.0 was used to record the collected data. SPSS 22.0 was used for statistical analysis.

Table 1 Basic characteristics of participating children. 


\begin{tabular}{|c|c|c|c|}
\hline & Male $(n=384)$ & Females $(n=221)$ & $\mathrm{P}$ \\
\hline \multicolumn{4}{|l|}{ Children's characteristics } \\
\hline Age (years), $\overline{\mathrm{X}}(\mathrm{S})$ & $4.4(1.0)$ & $4.4(1.2)$ & 0.919 \\
\hline Birth weight $(\mathrm{kg}), \overline{\mathrm{X}}(\mathrm{S})$ & $3.5(0.5)$ & $3.4(0.4)$ & 0.652 \\
\hline \multicolumn{4}{|l|}{$\begin{array}{l}\text { Anthropometric and blood pressure } \\
\text { measurements, median }\left(\mathrm{P}_{25}, \mathbf{P}_{75}\right)\end{array}$} \\
\hline Height $(\mathrm{cm})$ & $111.4(105.0,118.0)$ & $110.5(102.5,117.2)$ & 0.227 \\
\hline Weight (kg) & $10.4(8.8,12.6)$ & $10.1(8.3,12.2)$ & 0.094 \\
\hline $\mathrm{WC}(\mathrm{cm})$ & $54.9(51.0,62.0)$ & $55.0(51.0,62.0)$ & 0.748 \\
\hline BMI & $16.8(15.4,19.5)$ & $16.7(15.4,19.2)$ & 0.396 \\
\hline WHtR & $0.5(0.5,0.6)$ & $0.50(0.5,0.6)$ & 0.529 \\
\hline $\mathrm{DBP}(\mathrm{mmHg})$ & $90.0(85.0,99.0)$ & $90.0(84.0,96.0)$ & 0.273 \\
\hline $\mathrm{SBP}(\mathrm{mmHg})$ & $60.0(50.0,62.0)$ & $60.0(50.0,60.0)$ & 0.139 \\
\hline \multicolumn{4}{|l|}{ Weight and blood pressure status, $\mathbf{n}(\%)$} \\
\hline Healthy weight & $188(49.0)$ & $114(51.6)$ & \\
\hline Overweight & $54(14.1)$ & $31(14.0)$ & 0.797 \\
\hline Obesity & $142(37.0)$ & $76(34.4)$ & \\
\hline $\mathrm{WH}+\mathrm{R} \geq 0.5$ & $197(51.3)$ & $111(50.2)$ & 0.841 \\
\hline $\mathrm{WC} \geq \mathrm{P}_{\mathrm{S0}}$ & $209(54.5)$ & $132(59.7)$ & 0.184 \\
\hline Elevated BP & $69(18.0)$ & $38(17.2)$ & 0.783 \\
\hline \multicolumn{4}{|l|}{ Food preferences, n (\%) } \\
\hline Puffed foods $\geq$ once per week & $175(45.7)$ & $107(48.6)$ & 0.505 \\
\hline Deep fried foods $\geq$ twice per week & $59(15.3)$ & $33(15.1)$ & 0.947 \\
\hline $\begin{array}{l}\text { Potatoes and other root vegetables } \geq 4 \text { times } \\
\text { per week }\end{array}$ & $168(43.8)$ & $94(42.5)$ & 0.769 \\
\hline Drinks milk $\geq 6$ times per week & $179(46.6)$ & $107(48.4)$ & 0.729 \\
\hline Nuts $\geq 3$ times per week & $299(77.9)$ & $180(81.4)$ & 0.365 \\
\hline Sweets $\geq 3$ times per week & $101(26.3)$ & $60(27.1)$ & 0.82 \\
\hline Eat wheat and wheat products as staple food & $54(14.1)$ & $36(16.3)$ & 0.459 \\
\hline \multicolumn{4}{|l|}{ Eating habits, n (\%) } \\
\hline \multicolumn{4}{|l|}{ Appetite } \\
\hline Good & $239(62.2)$ & $131(59.3)$ & \\
\hline Average & $135(35.2)$ & $77(34.8)$ & 0.139 \\
\hline Poor & $10(2.6)$ & $13(5.4)$ & \\
\hline \multicolumn{4}{|l|}{ Eating speed } \\
\hline Fast & $90(23.4)$ & $41(18.5)$ & \\
\hline Average & $220(57.3)$ & $123(55.7)$ & 0.088 \\
\hline Slow & $74(19.3)$ & $57(25.8)$ & \\
\hline Eat while watching TV & $167(43.5)$ & $93(42.1)$ & 0.648 \\
\hline Snack while watching TV & $142(37.0)$ & $98(44.5)$ & 0.067 \\
\hline \multicolumn{4}{|l|}{ Other behaviours, median $\left(\mathbf{P}_{25}, \mathbf{P}_{75}\right)$} \\
\hline Sleep (hours) & $11.0(10.1,12.0)$ & $11.0(10.0,12.0)$ & 0.124 \\
\hline Physical activity (hours) & $1.0(1.0,2.00)$ & $1.0(1.0,2.0)$ & 0.601 \\
\hline \multicolumn{4}{|l|}{ Parental characteristics } \\
\hline \multicolumn{4}{|l|}{ Parental BMI, median $\left(\mathbf{P}_{25}, \mathbf{P}_{75}\right)$} \\
\hline Maternal BMI & $22.0(20.3,24.1)$ & $22.0(20.4,23.9)$ & 0.730 \\
\hline Paternal BMI & $25.1(22.8,27.8)$ & $25.5(23.1,28.0)$ & 0.876 \\
\hline \multicolumn{4}{|l|}{ Familial monthly income (¥), n (\%) } \\
\hline$<3000$ & $22(5.7)$ & $20(9.0)$ & 0.237 \\
\hline 3000 to 5000 & $90(23.4)$ & $45(20.4)$ & \\
\hline 5000 to 8000 & $130(33.9)$ & $65(29.4)$ & \\
\hline$>8000$ & $142(37.0)$ & $91(41.2)$ & \\
\hline \multicolumn{4}{|l|}{ Parental education level, n (\%) } \\
\hline Secondary school or less & $110(28.7)$ & $54(24.4)$ & 0.510 \\
\hline College or Bachelor's degree & $240(62.5)$ & $145(65.6)$ & \\
\hline Graduate degree & $34(8.9)$ & $22(10.0)$ & \\
\hline \multicolumn{4}{|l|}{ Maternal education level, n (\%) } \\
\hline Secondary school or less & $104(27.1)$ & $54(24.4)$ & 0.298 \\
\hline College or Bachelor's degree & $242(63.0)$ & $152(68.8)$ & \\
\hline Graduate degree & $38(9.9)$ & $15(6.8)$ & \\
\hline \multicolumn{4}{|l|}{ Parental control and guidance, $n(\%)$} \\
\hline $\begin{array}{l}\text { Encourage child to eat a diverse range of } \\
\text { foods }\end{array}$ & $202(52.6)$ & $116(52.5)$ & 0.978 \\
\hline Use food as a reward & $137(35.7)$ & $88(39.8)$ & 0.434 \\
\hline Limit the amounts of snacks & $324(84.4)$ & $173(78.3)$ & 0.103 \\
\hline
\end{tabular}

*significant at $P<0.05$.

SD, standard deviation; BMI, body-mass index; WC, waist circumference; WHtR, wasit-to-height ratio; DPB, diastolic blood pressure; SBP, systolic blood pressure; P, percentile; BP, blood pressure; ZBMI, standardized Z-score values of BMl; ZWC, standardized z-score values of WC; ZWHtR, standardized z-score values of WHtR. 


\section{Results}

Basic characteristics of participating children are shown in Table 1. approximately $14.0 \%$ of the children were overweight and $36.0 \%$ of the children were obese. $50.7 \%$ of the children had WHtR $\geq 0.5$ and $15.9 \%$ had elevated BP. Approximately half of the parents asked their children to eat a diverse assortment of foods. Approximately $40 \%$ of parents rewarded their children with food. Approximately $80 \%$ of the parents limited the amounts of snacks their children ingest. More than $40 \%$ of the children had the habit of eating their meals while watching TV or snacking while watching TV. The values of all variables were not significantly different between male and female children. The results suggest that dietary preferences, dietary habits and whether the parents exert control over the children's diets have no significant differences between male and female children.

Obesity indices difference between elevated and normal blood pressured group is displayed in Table 2. For male children, children with elevated BP had higher ZWC, ZWHtR and ZBMI than those with normal BP. Among male children, there was a higher prevalence of abdominal obesity (as determined by WHtR and WC) and overweight (as determined by BMI) in those with elevated BP than with normal BP. For female children, prevalence of abdominal obesity (as determined by WC) was higher in those with elevated BP than with normal BP.

Table 2 The difference of obesity indices between elevated and normal blood pressured group.

\begin{tabular}{|c|c|c|c|c|c|c|}
\hline & Male $(n=384)$ & & & Female $(\mathrm{n}=221)$ & & \\
\hline $\begin{array}{l}\text { Obesity } \\
\text { indices }\end{array}$ & $\begin{array}{l}\text { Elevated BP } \\
(\mathrm{n}=69)\end{array}$ & $\begin{array}{l}\text { Normal BP } \\
(\mathrm{n}=315)\end{array}$ & $\mathrm{P}$ & $\begin{array}{l}\text { Elevated BP } \\
(\mathrm{n}=38)\end{array}$ & $\begin{array}{l}\text { Normal BP } \\
(\mathrm{n}=183)\end{array}$ & $\mathrm{P}$ \\
\hline $\begin{array}{l}\text { ZWC, } \\
\text { median } \\
\left(\mathrm{P}_{25}, \mathrm{P}_{75}\right)\end{array}$ & $\begin{array}{l}2.13(0.69, \\
3.59)\end{array}$ & $\begin{array}{l}0.57(-0.17 \\
2.02)\end{array}$ & <. $001^{\star \star}$ & $\begin{array}{l}1.50(0.85 \\
2.95)\end{array}$ & $\begin{array}{l}0.83(0.2 \\
2.82)\end{array}$ & 0.068 \\
\hline $\begin{array}{l}\text { ZWHtR, } \\
\text { median } \\
\left(\mathrm{P}_{25}, \mathrm{P}_{75}\right)\end{array}$ & $2,00(0.19,3.09)$ & $\begin{array}{l}0.48(-0.35 \\
1.85)\end{array}$ & <.001** & $1.42(0.56,2.39)$ & $\begin{array}{l}1.07(0.09 \\
2.75)\end{array}$ & 0.335 \\
\hline $\begin{array}{l}\text { ZBMI, } \\
\text { median } \\
\left(\mathrm{P}_{25}, \mathrm{P}_{75}\right)\end{array}$ & $3.03(0.55,4.58)$ & $0.90(0.72,2.97)$ & $\begin{array}{l}<.001^{\star \star} \\
\end{array}$ & $1.82(0.32,3.25)$ & $\begin{array}{l}0.93(-0.01 \\
2.66)\end{array}$ & 0.099 \\
\hline $\begin{array}{l}\text { Overweight, } \\
\text { n (\%) }\end{array}$ & $49(71.0)$ & $153(48.6)$ & $0.001 *$ & $23(60.5)$ & $86(47.0)$ & 0.161 \\
\hline $\begin{array}{l}\text { WHtR } \geq \\
0.5, \mathrm{n}(\%)\end{array}$ & $47(68.1)$ & 148 (46.9) & $0.002^{*}$ & $21(55.2)$ & $86(47.0)$ & 0.442 \\
\hline $\begin{array}{l}W C \geq P_{80} \\
n(\%)\end{array}$ & $57(82.6)$ & $161(51.1)$ & <. $001^{\star \star}$ & $31(81.6)$ & $110(60.1)$ & $0.019 *$ \\
\hline
\end{tabular}


BP, blood pressure; ZBMI, standardized z-score values of BMl; ZWC, standardized z-score values of WC; ZWHtR, standardized z-score values of WHtR.

*significant at $\mathrm{P}<0.05$, ** significant at $\mathrm{P}<0.001$.

Univariate logistic regression results showed that for male children, all obesity indices, either numerical or categorical, were related to elevated blood pressure. For female children, only WC Category was associated with elevated blood pressure (supplementary Table 1). For multivariate analysis, BMI-related obesity indices and WC-related obesity indices were combined. Results showed that, among male children, when ZWC and ZBMI were included in the model together, ZWC had a stronger association with elevated BP. When ZWHtR and ZBMI were included in the model together, ZBMI had a stronger association (Table 3). Therefore, for male children, numerical obesity indices that had associations with elevated BP were, in decreasing order of strength: ZWC, ZBMI and ZWHtR. When BMI Category and WC Category were put in the model together, WC Category showed a stronger association. When WHtR Category and WC Category were put in the model together, WC Category was significant. When WHtR Category and BMI Category were put in the model together, neither of them was statistically significant. So, compared to BMI Category and WHtR Category, WC Category showed a stronger association with elevated BP in male children. For female children, when WHtR Category and WC Category were put together, WC Category was superior. Although no obesity indices were associated with elevated BP in other models, WC Category was almost significant $(P=0.054)$ when WC Category and BMI Category were analyzed together. The results suggested that, for female children, WC Category was also the obesity index that has the closest association with elevated BP (Table 3).

T able 3 Associations of obesity indices with elevated BP by logistic regressions. 


\begin{tabular}{|c|c|c|c|c|}
\hline \multirow[t]{2}{*}{ Variable } & \multicolumn{2}{|l|}{ Male } & \multicolumn{2}{|l|}{ Female } \\
\hline & OR $(95 \% \mathrm{Cl})$ & $\mathrm{P}$ & OR $(95 \% \mathrm{Cl})$ & $\mathrm{P}$ \\
\hline \multicolumn{5}{|l|}{ Model 1} \\
\hline ZBMI & $1.06(0.89,1.26)$ & 0.549 & $1.14(0.87,1.50)$ & 0.351 \\
\hline ZWC & $1.30(1.03,1.64)$ & $0.029 *$ & $1.06(0.82,1.38)$ & 0.667 \\
\hline \multicolumn{5}{|l|}{ Model 2} \\
\hline ZBMI & $1.27(1.05,1.55)$ & $0.016 *$ & $1.19(0.92,1.53)$ & 0.185 \\
\hline ZWHtR & $0.96(0.75,1.23)$ & 0.749 & $0.99(0.81,1.23)$ & 0.999 \\
\hline \multicolumn{5}{|l|}{ Model 3} \\
\hline BMI Category ${ }^{a}$ & $1.37(0.68,2.76)$ & 0.385 & $1.11(0.47,2.62)$ & 0.811 \\
\hline WC Category ${ }^{b}$ & $3.64(1.63,8.16)$ & $0.002^{*}$ & $2.81(0.98,8.03)$ & 0.054 \\
\hline \multicolumn{5}{|l|}{ Model 4} \\
\hline BMI Category & $1.88(0.93,3.84)$ & 0.081 & $1.69(0.67,4.28)$ & 0.269 \\
\hline WHtR Category ${ }^{c}$ & $1.87(0.93,3.77)$ & 0.081 & $1.02(0.41,2.57)$ & 0.963 \\
\hline \multicolumn{5}{|l|}{ Model 5} \\
\hline WC Category & $4.05(1.66,9.90)$ & $0.002^{*}$ & $3.68(1.22,11.07)$ & $0.021^{*}$ \\
\hline WHtR Category & $1.11(0.51,2.41)$ & 0.800 & $0.72(0.29,1.76)$ & 0.466 \\
\hline
\end{tabular}

All models were adjusted by age and amount of physical activity.

* significant at $\mathrm{P}<0.05$.

a BMI category: overweight/ obese verses healthy.

${ }^{b}$ WC category: $\mathrm{WC} \geq \mathrm{P}_{80}$ versus $\mathrm{WC}<\mathrm{P}_{80}$.

${ }^{c}$ WHtR category: WhtR $\geq 0.5$ versus $\mathrm{WHtR}<0.5$.

Since ZWC and WC Category were the numerical and categorical obesity indices that most closely associated with elevated BP among the preschool children, respectively, Tables 4 and 5 show the independent factors for these two variables. For male children, parental BMI, fast eating speed, good appetite, snacking while watching TV and eating wheat and wheat-based products as staple food were positively associated with ZWC. Male children with faster eating speed, better appetite, habits of snacking while watching TV and eating wheat-based products as staple food had larger ZWC. For female children, maternal BMI and a good appetite were positively associated with ZWC. Male children with better appetite 
also had larger ZWC. For both male and female children, parental encouragements to eat a diverse assortment of foods were negatively associated with ZWC (Table 4). Children whose parents asked to eat a diverse assortment of foods had smaller ZWC.

Table 4 Independent factors for ZWC by multivariate stepwise linear regression.

\begin{tabular}{|c|c|c|c|c|}
\hline \multirow[t]{2}{*}{ Independent variables } & \multicolumn{2}{|l|}{ Male } & \multicolumn{2}{|l|}{ Female } \\
\hline & $\mathrm{B}(95 \% \mathrm{Cl})$ & $P$ & $\mathrm{~B}(95 \% \mathrm{Cl})$ & $P$ \\
\hline Age & $0.480(0.310,0.650)$ & $<.001$ & $\begin{array}{l}0.363(0.179 \\
0.546)\end{array}$ & $\begin{array}{l}< \\
0.001\end{array}$ \\
\hline Paternal BMI & $0.092(0.047,0.137)$ & $<.001$ & - & - \\
\hline Maternal BMI & $0.092(0.040,0.143)$ & 0.001 & $\begin{array}{l}0.141(0.073 \\
0.209)\end{array}$ & $\begin{array}{l}< \\
0.001\end{array}$ \\
\hline $\begin{array}{l}\text { Wheat and wheat-based products as } \\
\text { staple food }{ }^{\text {a }}\end{array}$ & $0.756(0.270,1.241)$ & 0.002 & - & - \\
\hline Appetite ${ }^{\mathrm{b}}$ & $0.556(0.197,0.914)$ & 0.002 & $\begin{array}{l}0.870(0.496 \\
1.244)\end{array}$ & $<.001$ \\
\hline Eating speed ${ }^{c}$ & $0.571(0.277,0.864)$ & $<.001$ & - & - \\
\hline $\begin{array}{l}\text { Parents courage eating a wide variety of } \\
\text { foods } d\end{array}$ & $-0.677(-1.081,-0.274)$ & 0.001 & $\begin{array}{l}-0.700(-1.144 \\
-0.257)\end{array}$ & 0.002 \\
\hline Snack while watching TV ${ }^{e}$ & $0.373(0.026,0.721)$ & 0.035 & - & - \\
\hline
\end{tabular}

$\mathrm{BMI}$, body-mass index.

a Wheat and wheat-based products as their staple food: "yes" versus "no".

${ }^{b}$ The three levels of appetite: poor, average, good, were given the values 1,2 , and 3 , respectively.

${ }^{\mathrm{c}}$ The three eating speeds: slow, average, fast, were given the values of 1,2 and 3 , respectively.

d Parents encourage the child to eat diverse assortment of food: "yes" versus "no".

e Snacks while watching TV: "yes" versus "no".

Table 5 showed that, for male children, birth weight, parental BMI, a good appetite and eating speed were positively associated with WC-determined abdominal obesity. For female children, maternal BMI, good appetite and fast eating speed were positively associated with WC-determined abdominal obesity, whereas milk intake was negatively associated with abdominal obesity. The risk of abdominal obesity increased 
1.375 times in males and 1.631 times in females if appetite increased one level. If eating speed increased one level, the risk of abdominal obesity increased 1.165 times in males and 0.905 times in females. Children who drank milk at least 6 times per week had a 0.546 times lower risk of abdominal obesity than those did not.

Table 5 Independent factors for WC-determined abdominal obesity by multivariate stepwise logistic regression.

\begin{tabular}{|c|c|c|c|c|}
\hline \multirow[t]{2}{*}{ Independent variables } & \multicolumn{2}{|l|}{ Male } & \multicolumn{2}{|l|}{ Female } \\
\hline & OR $(95 \% \mathrm{Cl})$ & $\mathrm{P}$ & OR $(95 \% \mathrm{Cl})$ & $P$ \\
\hline Age & $1.653(1.286,2.124)$ & $<0.001$ & $1.445(1.093,1.910)$ & 0.010 \\
\hline Birthweight & $1.316(1.001,1.713)$ & 0.041 & $1.110(0.998,1.234)$ & 0.054 \\
\hline Paternal BMI & $1.117(1.045,1.194)$ & 0.001 & - & - \\
\hline Maternal BMI & $1.093(1.012,1.180)$ & 0.024 & - & - \\
\hline Appetite $^{a}$ & $2.375(1.443,3.908)$ & 0.001 & $2.631(1.479,4.682)$ & 0.001 \\
\hline Eating speed ${ }^{b}$ & $2.265(1.486,3.454)$ & $<0.001$ & $1.905(1.109,3.270)$ & 0.019 \\
\hline Milk intake ${ }^{c}$ & - & - & $0.454(0.238,0.866)$ & 0.016 \\
\hline
\end{tabular}

a The three levels of appetite: poor, average, good, were given the values 1,2 , and 3 , respectively.

${ }^{b}$ The three eating speeds: slow, average, fast, were given the values of 1,2 and 3 , respectively.

${ }^{\mathrm{c}}$ Milk intake: drinks milk $\geq 6$ times per week versus drinks milk $<6$ times per week.

\section{Discussion}

Our study compared the magnitudes of association between elevated BP and each of: BMI, WC and WHtR, among preschool children aged 2-6. The results suggested that WC and abdominal obesity defined by WC were the strong factors for elevated BP. It was also found that, among familial factors, certain food-related factors have a strong association with WC and abdominal obesity. This conveys what we need to target in preventing obesity and adulthood hypertension in the future.

In our study, the regression models showed that WC and WC Category showed a stronger positive association with BP than other obesity indices. These results were similar to some previous studies. A study performed on a Brazilian sample aged 8 to 10 years confirmed that abdominal obesity determined by WC had the closest association with elevated blood pressure, as compared to $\mathrm{BMI}$ and percentage of total body fat (PBF) [10]. The risk of hypertension in Mexican children and adolescents were found to be higher in those with increased WC compared to those with high BMI [31]. Based on the results of some 
other studies, whether WC is the best predictor of elevated BP is still under debate. The Chinese National Cross-sectional Study of Children and Adolescents Aged 9-17 concluded that WHtR had a stronger ability to predict elevated blood pressure after it was adjusted based on BMI values, which was different from our conclusion [32]. A cohort study in China showed that high BMI, but not WC or PBF, was associated with a higher risk of childhood hypertension [5]. However, past studies only analyzed either numerical or categorical obesity indices in a single study, never both. In contrast, our research included both types of obesity indices, which may provide a more comprehensive analysis of the association between obesity indices and elevated BP. Our results suggested that WC should be screened for decrease the risk of elevated BP.

Because in our study, WC and WC Category showed a strong association with BP, we determined the potential familial factors that associate with WC and WC Category in order to provide the prevention strategy. According to the results, apart from birth weight and parental BMI, all other independent factors were related to dietary preference, eating behaviour and parents' feeding style. In the current study, for both male and female children, a good appetite predicted increased WC and increased risk of abdominal obesity, which is also what previous studies have found [33]. A greater interest in food and a more avid appetite, enjoyment of food, food responsiveness, desire to drink and emotional overeating have been consistently associated with overweight/obesity in childhood.

In the current study, it seemed that the faster they eat, the greater their waist circumference in males, and the greater risk of developing abdominal obesity in males and females. Although many studies have claimed the positive relationship between eating speed and general obesity in children, few studies investigate the association of eating speed with abdominal obesity. A recent study based on a nationwide school-based intervention program of obesity in China showed that eating fast increased the risk of abdominal obesity defined by WC among school students [34]. This result was consistent with ours. Many previous researches had found that slowness in eating was a type of food avoidance behaviour, and it negatively correlated with obesity [33]. There are two possible reasons why eating slowly is good for maintaining a healthy weight. First, eating slowly may enhance the thermic effect of food, which benefits weight control [35].Second, eating speed may influence gastrointestinal satiety hormones, which can control appetite and influence food intake [36].

In our study, the habit of snacking while watching TV was also found to be an independent factor for an increase in WC in male children. Previous studies had showed that there was a positive relationship between television viewing time and BMI or WC, which might be due to increase in sedentary behavior, the power of advertising on food and increase of food intake [37]. Obviously, snacking while watching TV can cause irregular and excess food intake, leading to overweight and obesity. One study claimed that reducing TV viewing time to 1 hour per week could prevent $29 \%$ of the obesity [38]. Therefore, parents should reduce the amount of time their children spend watching TV and forbid the practice of snacking while watching TV.

Our study also concluded that encouraging children to eat a wide variety of foods was negatively associated with WC, which was similar with a Polish research studying 5-year-olds concluded [27]. Eating 
a diverse range of foods may promote proper physical development and therefore can help in weightcontrolling. Early introduction of a diverse assortment of foods can also broaden a child's food preferences and help the child develop enjoyment for healthy foods. On the other hand, limited exposure to novel foods can lead to solidify the child's preferences for unhealthy foods, consequently leading to an elevated risk of being overweight or obese $[39,40]$.

Our study found that for girls, milk intake is a protective factor for obesity. Many previous studies also have found that milk intake negatively correlates with both body weight and body fat $[41,42]$. Using milk as a substitute for sugary beverages can slow the increase of weight and BMI [43]. This may be because milk contains calcium, conjugated linoleic acid and milk proteins, which all promote proper development, making milk beneficial for maintaining weight [44]. However, the relationship between fat content of milk and weight loss is still under debate $[42,44]$.

Our study showed that male children who eat wheat and wheat-based products as their staple food have a bigger waist circumference than those who do not. In northern China, it is widespread to have wheat and wheat-based products, such as noodles and steamed buns, as staple food [14]. The prevalence of obesity is also higher in northern China, as compared to southern China, where the staple food is rice $[14,45]$. Compared to rice, wheat absorbs less water when cooked, so it is calorically denser. There is a strong correlation between obesity and intake of calorically dense foods [46].

In the current study, it was found that parental BMI was a strong factor for WC and abdominal obesity in males. A study performed on Beijing children showed that the risk of male children becoming obese is higher if both of their parents are obese, compared to if only one of their parents is obese. In female children, however, the risk of obesity is the same whether both parents are obese or if only one parent is obese [47]. These results are partially similar to what we found. The fact that parental BMI is associated with the child's weight can be explained by shared genetics and shared environments. Studies have found 50 polymorphic genes related to BMI [48]. With respect to a shared environment, parental habits, such as dietary habits and exercise habits, can influence the child's habits.

This study has several limitations. Firstly, cross-sectional studies cannot confirm causality, so further cohort studies are required. Secondly, the BP was obtained from a single visit, but not clinically diagnosed hypertension. Lastly, a larger sample size would have been better.

\section{Conclusion}

WC is more closely associated with elevated BP. Genetics and familial dietary habits are the main predictors of increased WC and abdominal obesity in preschool children. High parental BMI, eating wheat and wheat-based products as staple food, good appetite, fast eating speed and snacking while watching TV were risk factors for increased WC or abdominal obesity. Parental encouragement to eat a diverse assortment of foods and drinking milk were protective factors.

\section{Abbreviations}


BMI: body mass index; WC: waist circumference; WHtR: waist-to-height ratio; PBF: percentage of total body fat.

\section{Declarations}

\section{Acknowledgements}

Thanks to all the participants and the medical staff.

\section{Availability of data and materials}

The datasets used and analyzed during the current study are available from the corresponding author on reasonable request.

\section{Funding Information}

This work was supported by Chinese National Natural Science Foundation Institutional Review Board (grant number 71774173); China Medical Board (grant number 18-291); and Technology Department of Liaoning province (grant number 2017225004).

\section{Authorship' contributions}

$\mathrm{XT}$ is the first author. DW is the corresponding author. DW designed the study. $\mathrm{YL}, \mathrm{JH}, \mathrm{LZ}$ and $\mathrm{LJ}$ collected the data. XT and YM analyzed the data and XT drafted the manuscript. XT, YL and ND contributed to the interpretation of the results and critical revision of the manuscript for important intellectual content. All authors have read and approved the final manuscript.

\section{Ethics approval and consent to participate}

This study was approved by the Ethics Committee of Institute of Health Science (Ethics Approval No. [2017] 055), China Medical University. The consent processes were documented through audio recorder pens.

\section{Consent for publication}

Not applicable

\section{Competing interests}

The authors declare that they have no competing interests.

\section{References}

1. Chen $X$, Wang Y. Tracking of blood pressure from childhood to adulthood: a systematic review and meta-regression analysis. Circulation 2008; 117: 3171-3180. 
doi:10.1161/CIRCULATIONAHA.107.730366

2. McCrindle BW. Assessment and management of hypertension in children and adolescents. Nat Rev Cardiol 2010; 7: 155-163. doi:10.1038/nrcardio.2009.231

3. Din-Dzietham R, Liu Y, Bielo MV, Shamsa F. High blood pressure trends in children and adolescents in national surveys, 1963 to 2002. Circulation 2007; 116: 1488-1496.

doi:10.1161/CIRCULATIONAHA.106.683243

4. Larkins NG, Teixeira-Pinto A, Craig JC. The prevalence and predictors of hypertension in a National Survey of Australian Children. Blood Press 2018; 27: 41-47. doi冈10.1080/08037051.2017.1380502

5. Xu RY, Zhou YQ, Zhang XM, Wan YP, Gao XC. Body mass index, waist circumference, body fat mass, and risk of developing hypertension in normal-weight children and adolescents. Nutr Metab Cardiovasc Dis 2018; 28: 1061-1066.

6. Zhang Q, Yang L, Zhang Y, Zhao M, Liang Y, Xi B. Hypertension Prevalence Based on Three Separate Visits and Its Association With Obesity Among Chinese Children and Adolescents. Front Pediatr 2019; 7: 307.

7. Wang SR, Zhu YB, Cheng Y, Zhang YX. Profiles of blood pressure among children and adolescents

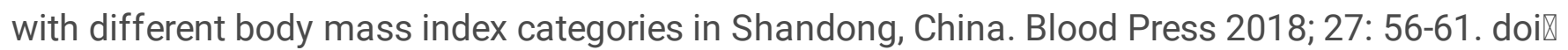
10.3389/fped.2019.00307

8. Wang M, Chu C Mu J. Relationship between body mass index changes and blood pressure changes from childhood to adulthood in a general Chinese population: a 26 year cohort follow-up study. Blood Pressure 2016; 25: 319-326. doi冈10.3109/08037051.2016.1168969

9. Pazin DC, Rosaneli CF, Olandoski M, Oliveira ERN, Baena CP, Figueredo AS et al. Waist Circumference is Associated with Blood Pressure in Children with Normal Body Mass Index: A Cross-Sectional Analysis of 3,417 School Children. Arq Bras Cardiol 2017;109: 509-515. doi冈10.5935/abc.2017016

10. Cruz NRC, Cardoso PC, Frossard T, Oliveira Ferreira F, Brener S, Freitas Gomides F et al. Waist circumference as high blood pressure predictor in school age children. Cien Saude Colet 2019; 24: 1885-1893. doi: 10.1590/1413-81232018245.18012017

11. Dong B, Wang Z, Wang HJ, Ma J et al. Associations between adiposity indicators and elevated blood pressure among Chinese children and adolescents. J Hum Hypertens 2015; 29: 236-240. doi区 10.1038/jhh.2014.95

12. Lopez-Gonzalez D, Miranda-Lora A, Klunder-Klunder M, Queipo-Garca G, Bustos-Esquivel M, Paez-Villa $M$ et al. Diagnostic Performance of Waist Circumference Measurements for Predicting Cardiometabolic Risk in Mexican Children. Endocr Pract 2016; 22: 1170-1176. doi区 10.4158/EP161291.OR

13. Sardinha LB, Santos DA, Silva AM, Grøntvedt A, Andersen LB, Ekelund U et al. A Comparison between BMI, Waist Circumference, and Waist-To-Height Ratio for Identifying Cardio-Metabolic Risk in Children and Adolescents. PLoS One 2016; 11: e0149351. doi囚10.1371/journal.pone.0149351

14. Liberali R, Kupek E Assis MAA. Dietary Patterns and Childhood Obesity Risk: A Systematic Review. Child Obes 2020; 16: 70-85. doi囚10.1089/chi.2019.0059 
15. Tang $\mathrm{D}$, Bu T Dong X. Are parental dietary patterns associated with children's overweight and obesity in China? BMC Pediatr 2020; 20: 12. doi囚10.1186/s12887-020-1910-z

16. Boswell N, Byrne R Davies PSW. Family food environment factors associated with obesity outcomes in early childhood. BMC Obes 2019; 6: 17. doi $10.1186 /$ s40608-019-0241-9

17. Webber L, Hill C, Saxton J, Van Jaarsveld $\mathrm{CH}$, Wardle J. Eating behaviour and weight in children. Int J Obes (Lond) 2009; 33: 21-28. doi囚10.1038/ijo.2008.219

18. Yu D, Zhang X, Xiang YB, Yang G, Li H, Gao YT et al. Adherence to dietary guidelines and mortality: a report from prospective cohort studies of 134,000 Chinese adults in urban Shanghai. Am J Clin Nutr.2014; 100: 693-700. doið10.3945/ajcn.113.079194

19. He Y, Ma G, Zhai FY, Li YP, Hu YS, Edith F et al. Dietary patterns and glucose tolerance abnormalities in Chinese adults. Diabetes Care. 2009; 32:1972-1976. doi囚10.2337/dc09-0714

20. Marille VZ, Myriam H, Lucille G, Kerry G, Guido B, Wouter $H$ et al. Dietary patterns and their associations with childhood obesity in China. Br J Nutr. 2015; 113: 1978-1984. doi区 $10.1017 /$ S0007114515001154.

21. Pauline WJ, Sabine JR, Vincent WVJ, Joreintje DM, Hein R, Albert $\mathrm{H}$ et al. Children's eating behavior, feeding practices of parents and weight problems in early childhood: results from the populationbased Generation R Study. International Journal of Behavioral Nutrition and Physical Activity 2012; 9:130 doi冈10.1186/1479-5868-9-130.

22. Spence JC, Carson V, Casey L, Boule N. Examining behavioural susceptibility to obesity among Canadian pre-school children: the role of eating behaviours. Int J Pediatr Obes 2011; 6: e501-507. doi区 $10.3109 / 17477166.2010 .512087$

23. Strader AD, Woods SC. Gastrointestinal Hormones and Food Intake. Gastroenterology 2005; 128 : 175-191. doiø10.1053/j.gastro.2004.10.043

24. Escobar-Chaves SL , Christine MM, Robert CA, Greisinger A, Murray NG, Brehm B. The Fun Families Study: Intervention to Reduce Children's TV Viewing. Child Obes.2010; 18: S99-S101.

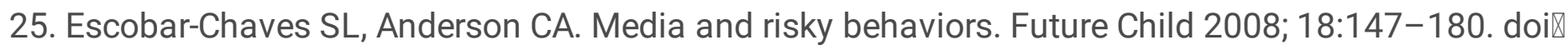
10.1353/foc. 0.0007

26. Ontai LL, Sutter C, Sitnick S, Shilts MK, Townsend MS et al. Parent Food-Related Behaviors and Family-Based Dietary and Activity Environments: Associations with BMI z-Scores in Low-Income Preschoolers. Child Obes.2019; Suppl 1: S55-S63. doi囚10.1089/chi.2019.0105

27. Lipowska M, Lipowski M, Jurek P, Jankowska AM, Pawlicka P. Gender and Body-Fat Status as Predictors of Parental Feeding Styles and Children's Nutritional Knowledge, Eating Habits and Behaviours. Int J Environ Res Public Health 2018; 15: 852. doi囚10.3390/ijerph15050852

28. Mi J, Wang T, Meng L. Development of blood pressure reference standards for Chinese children and adolescents. Chin d Evid Based Pediat 2010; 5: 4-14. (In Chinese)

29. Li H, Zong X, Ji C. Body mass index cut offs for overweight and obesity in Chinese children and adolescents aged 2ه18 years. Chin J Epidemiol 2010; 31: 616-620. (In Chinese) 
30. Meng L, Mi J, Cheng H. Using waist circumference and waist-to-height ratio to access central obesity in children and adolescents. Chin J Evid Based Pedlatr 2007; 2: 245-252. (In Chinese)

31. Reyes de la Cruz L, Sanos FH, Flores HS, Klunder KM. Increase in body mass index and waist circumference is associated with high blood pressure in children and adolescents in Mexico city. Arch Med Res 2009; 40: 208-215. doi囚10.1016/j.arcmed.2009.02.009

32. Dong B, Wang ZQ, Arnold LW, Yang Y, Ma J. Role of waist measures in addition to body mass index to assess the hypertension risk in children. Blood Press 2016; 25, 344-350. doi $\bigotimes$ 10.1080/08037051.2016.1182420

33. Spence JC, Carson V, Casey L, BOULE N. Examining behavioural susceptibility to obesity among Canadian pre-school children: the role of eating behaviours. Int J Pediatr Obes 2011; 6: e501-507. doið 10.3109/17477166.2010.512087

34. Zeng, X, Cai L, Ma J, Ma YH, Jing J, Chen YJ. Eating fast is positively associated with general and abdominal obesity among Chinese children: A national survey. Scientific Reports 2018; 8: 10.1038/s41598-018-32498-9. doiه10.1038/s41598-018-32498-9

35. Reddy NL, Peng CJ, Carreira MC, Halder L, Hattersley J, Piya MK. Enhanced Thermic Effect of Food, Postprandial NEFA Suppression and Raised Adiponectin in Obese Women Who Eat Slowly. Clin Endocrinol. 2015; 82: 831-837. doi囚10.1111/cen.12652

36. Galhardo J, Hunt LP, Lightman SL, Sabin MA, Bergh C, Sodersten P et al. Normalizing Eating Behavior Reduces Body Weight and Improves Gastrointestinal Hormonal Secretion in Obese Adolescents. The Journal of Clinical Endocrinology \& Metabolism.2012; 97: E193-E201. doi囚10.1210/jc.2011-1999

37. Bharati S, Pal M, Shome SP, Roy P, Dhara P, Bharati. Influence of socio-economic status and television watching on childhood obesity in Kolkata. Journal of Comparative Human Biology 2017; 68: 487-494. doi囚10.1016/j.jchb.2017.08.005

38. Dietz W, Gortmaker S. TV or not TV: Fat is the question. Pediatrics 1993; 91: 499-500.

39. Scaglioni S, Salvioni M, Galimberti C. Influence of parental attitudes in the development of children eating behaviour. Br J Nutr 2008; 99 Suppl 1: S22-25. doiه10.1017/S0007114508892471

40. Skinner JD, Carruth BR, Bounds W, Ziegler P, Reidy K. Do Food-Related Experiences in the First 2 Years of Life Predict Dietary Variety in School-Aged Children? Journal of Nutrition Education and Behavior 2002; 34: 310-315. doi $10.1016 /$ S1499-4046(06)60113-9

41. Barba G, Troiano E, Russo P, Venezia A, Siani A. Inverse association between body mass and frequency of milk consumption in children. Br J Nutr 2005; 93: 15-19. doiø10.1079/BJN20041300

42. Huh SY, Rifas-Shiman SL, Rich-Edwards JW, Taveras EM, Gillman MW. Prospective association between milk intake and adiposity in preschool-aged children. J Am Diet Assoc 2010; 110: 563-570. doi囚10.1016/j.jada.2009.12.025

43. Zheng M, Rangan A, Allman-Farinelli M, Rohde JF, Olsen NJ, Heitman BL. Replacing sugary drinks with milk is inversely associated with weight gain among young obesity-predisposed children. $\mathrm{Br} J$ Nutr 2015; 114: 1448-1455. doi冈10.1017/S0007114515002974 
44. Vanderhout SM, Birken CS, Parkin PC, Gerald L, Yang C, Deborah LO et al. Relation between milk-fat percentage, vitamin D, and BMI z score in early childhood. Am J Clin Nutr 2016; 104: 1657-1664. doi区 10.3945/ajcn.116.139675

45. Zhang L, Wang Z, Wang X, Chen Z, Shao L, Tian Y et al. Prevalence of overweight and obesity in China: Results from a cross-sectional study of 441 thousand adults, 2012-2015. Obes Res Clin Pract 2020; 14: 119-126. doi $₫ 10.1016 /$ j.orcp.2020.02.005

46. Shi Z, Taylor AW, Hu G, Gill T, Wittert G. Rice intake, weight change and risk of the metabolic syndrome development among Chinese adults: the Jiangsu Nutrition Study (JIN). Asia Pac J Clin Nutr 2012; 21: 35-43.

47. Li H, Guo H, Huang Y. Influence of parental overweight and obesity on childhood overweight and obesity. Chin J Sch Health 2016; 21: 239-242.(In Chinese)

48. Wen W, Zheng W, Okada Y, Takeuchi F, Tabara Y, Hwang J et al. Meta-analysis of genome-wide association studies in East Asian-ancestry populations identifies four new loci for body mass index. Hum Mol Genet 2014; 23: 5492-5504. doi囚10.1093/hmg/ddu248

\section{Supplementary Files}

This is a list of supplementary files associated with this preprint. Click to download.

- XiaoSupplementarytable1.docx 